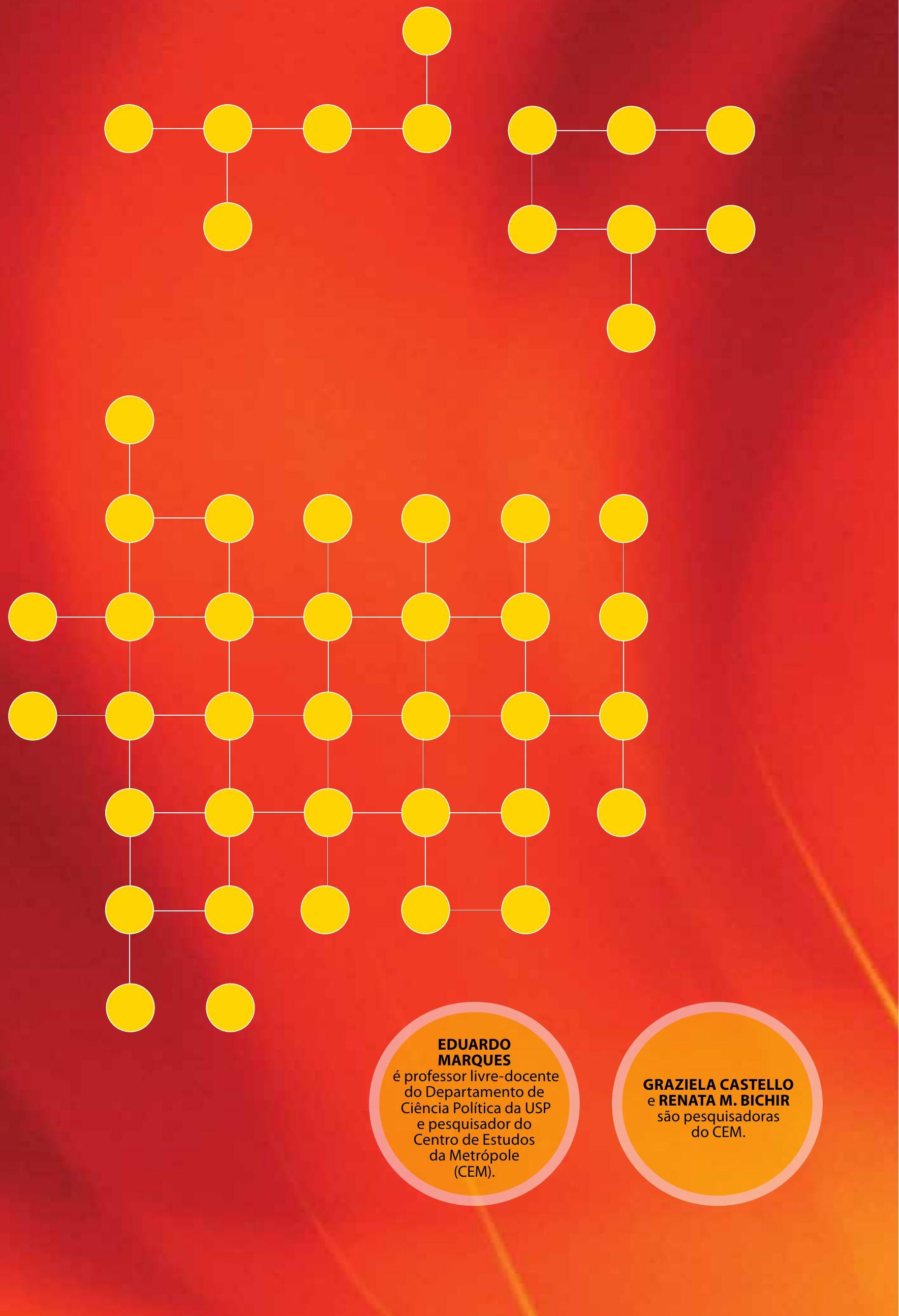




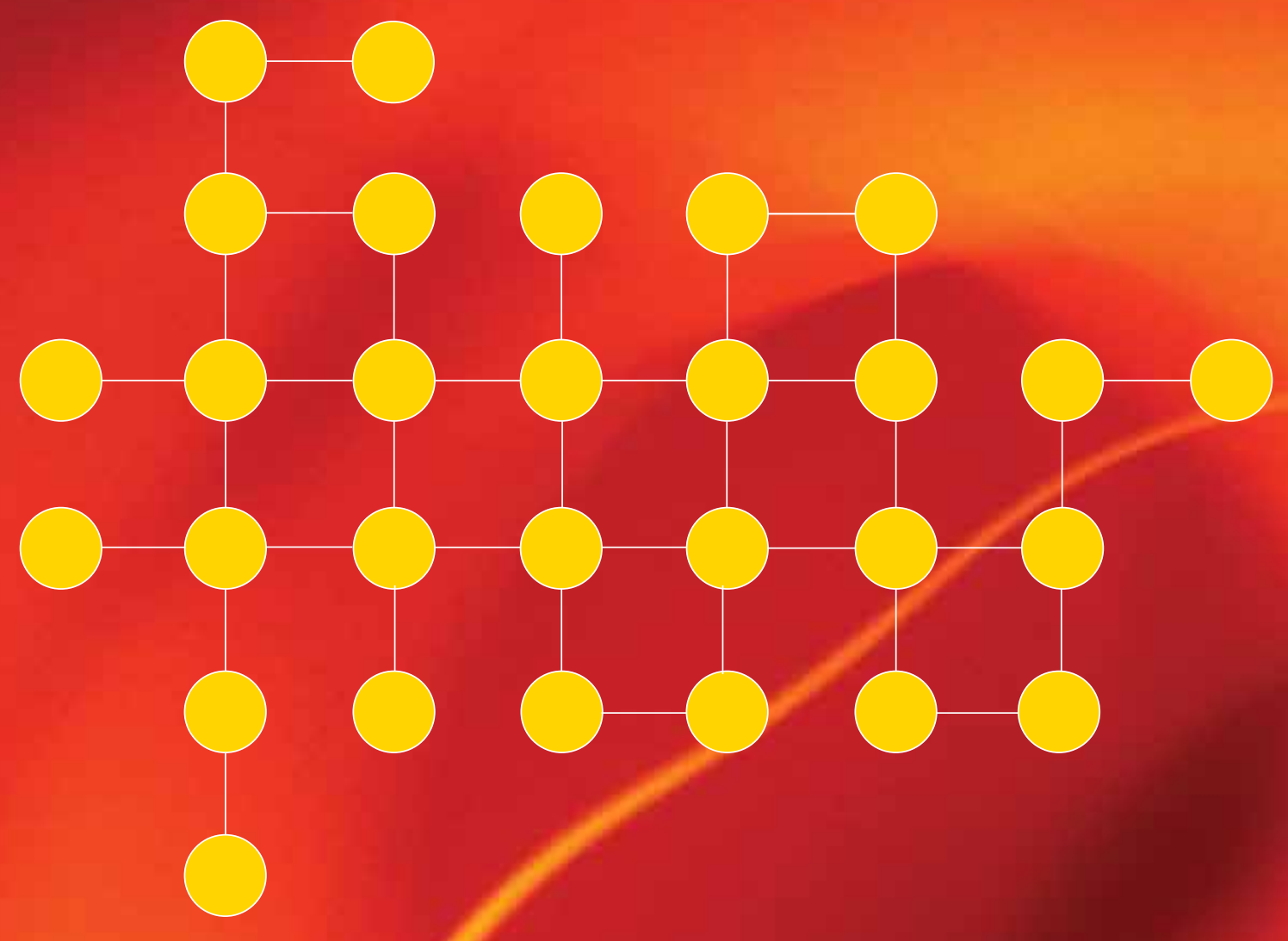

\section{REDES PESSOAIS}

\section{E VULNERABILIDADE}

\section{SOCIAL EM SÃO PAULO}

E SALVADOR

Eduardo Marques,

Graziela Castello e Renata M. Bichir 


\section{RESUMO}

Redes sociais têm sido constantemente citadas como importantes elementos na definição de situações sociais. Este artigo discute redes pessoais de indivíduos em situação de pobreza em doze localidades nas cidades de São Paulo e Salvador, comparando os padrões gerais observados. Em seguida, o artigo realiza uma análise quantitativa da associação de tais redes, assim como de atributos dos indivíduos, com a presença de situações de vulnerabilidade social. Os resultados indicam a importância dos tipos de redes e de sociabilidade na explicação das situações de pobreza urbana.

Palavras-chave: redes pessoais, pobreza, vulnerabilidade social, São Paulo, Salvador.

\section{ABSTRACT}

Social networks have often been cited as key element in shaping social situations. This article discusses the social networks of poor individuals in 12 locations in the cities of São Paulo e Salvador, by comparing the patterns found. After that, it analyzes quantitatively the association between those networks, as well as the attributes of individuals, and where the social vulnerability takes place. The results indicate the importance of the types of networks and of sociability to explain situations of urban poverty.

Keywords: social networks, poverty, social vulnerability, São Paulo, Salvador. 


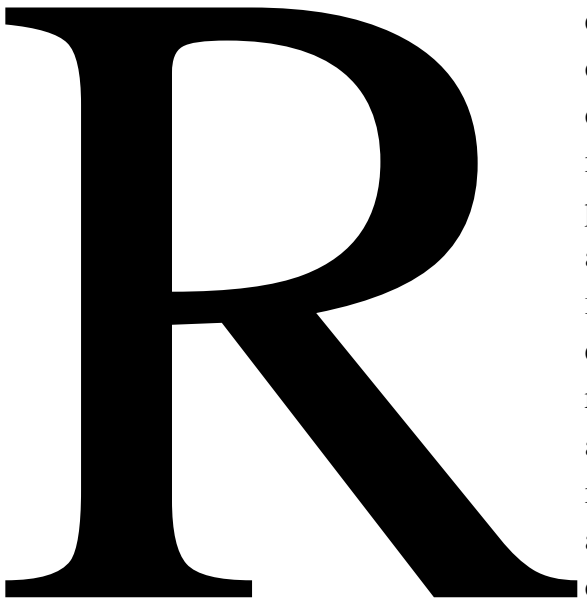

edes sociais têm sido cada vez mais consideradas como elementos importantes na construção de uma grande variedade de processos, desde a mobilização política em movimentos sociais ou partidos políticos (Mische, 2008; Hedstrom et al., 2000), até as ações e a estrutura de relações formais e informais entre as elites políticas e econômicas (Heinz et al., 1997) ou na estruturação de áreas de políticas públicas (Knoke et al., 1996), entre muitos outros temas. Outro número significativo de estudos tem examinado as redes pessoais, aquelas que cercam os indivíduos em particular. Essas análises visam estudar os efeitos da sociabilidade de diversos grupos sociais para compreender como os laços sociais são construídos e transformados (Bidart \& Lanevu, 2005; Degenne, 2009) e suas consequências para fenômenos como integração social, imigração e apoio social (Campbell \& Lee, 1992).

No caso específico da pobreza, a literatura tem estabelecido de forma cada vez mais eloquente como tais redes medeiam o acesso a recursos materiais e imateriais e, ao fazê-lo, contribuem de forma destacada para a reprodução das condições de privação e das desigualdades sociais. A integração das redes ao estudo da pobreza pode permitir a construção de análises que escapem dos polos analíticos da responsabilização individual dos pobres por sua pobreza (e seus atributos), assim como de análises sistêmicas que foquem apenas nos macroprocessos e constrangimentos estruturais que cercam o fenômeno. A literatura brasileira sobre o tema tem sido marcada por uma oposição entre enfoques centrados nesses dois campos, embora os últimos anos tenham assistido a uma clara hegemonia dos estudos baseados em atributos e ações individuais para a explicação da pobreza. Parece-nos evidente que tanto constrangimentos e processos supraindividuais (incluindo os econômicos) quanto estratégias e credenciais dos indivíduos importam para a constituição e a reprodução de situações de pobreza. Entretanto, essas devem ser analisadas no cotidiano dos indivíduos, de maneira que compreendamos de que forma medeiam o seu acesso a mercados, ao Estado e às trocas sociais que provêm bem-estar (Esping-Andersen, 2000).

Este artigo pretende contribuir para esse debate discutindo as características das redes pessoais de indivíduos em situação de pobreza em doze locais das cidades de São Paulo e Salvador, totalizando 362 redes, e sua associação com vulnerabilidade social, medida de forma composta considerando a presença de trabalho, trabalho com algum grau de proteção, condições habitacionais e estrutura familiar. Embora todos os entrevistados sejam pobres, as situações de vulnerabilidade diferenciam os indivíduos mais precários entre os pobres. $\mathrm{O}$ trabalho dá continuidade à pesquisa anterior que estudou as redes pessoais de 209 indivíduos em situação de pobreza e 30 indivíduos de classe média, em sete locais apenas em São Paulo (Marques, 2010). A escolha das duas cidades visou cobrir situações muito diferentes em termos urbanos, do mercado de trabalho, da estrutura social e dos padrões de pobreza.

A estrutura do artigo segue as etapas da construção desse exercício analítico. A próxima seção situa teoricamente o estudo, assim como especifica as principais ferramentas de pesquisa utilizadas. A segunda seção apresenta comparativamente as características básicas das redes e a terceira seção testa os condicionantes da vulnerabilidade social. Ao final, retornamos os principais achados. 


\section{CONECTANDO CONCEITUALMENTE REDES E POBREZA}

Em termos teóricos, definimos pobreza como o conjunto heterogêneo de situações associadas a privações de bem-estar sendo, portanto, um fenômeno multidimensional. Desse modo, envolve um conjunto amplo de dimensões econômicas, mas também sociais, em sentido amplo (incluindo práticas, padrões de sociabilidade, referenciais culturais que dão sentido à própria condição, etc.), assim como políticas (visto que se vinculam às opções de vida, às decisões tomadas e às estratégias seguidas pelos indivíduos, apontando, portanto, para dimensões associadas à liberdade de escolha entre alternativas). Os processos de produção e reprodução de tais condições também são complexos e multifacetados, embora certamente ultrapassem processos e elementos propriamente econômicos, como considerado por uma parte expressiva dos debates, em especial no Brasil.

Seguindo Esping-Andersen (2000) e Mustered, Murie e Kesteloot (2006), consideramos que o bem-estar pode ser provido simultaneamente ao menos por três grandes esferas - Estado, mercados e comunidade/ sociabilidade/famílias. Além disso, as condições de acesso a essas esferas podem também variar intensamente entre indivíduos, assim como entre momentos no tempo. Os debates

1 A homofilia diz respeito a cada díade em particular e a cada atributo social especificamente. Assim, pode-se perguntar se uma dada relação é homofílica em relação a sexo ou cor da pele ou classe social. Mas também podemos calcular a proporção, em uma dada rede, de relações em queosenvolvidos nas díades pertencem ao mesmo sexo, têm a mesma cor da pele ou classe social. Isso permite gerar indicadores do grau de homofilia média nas redes. acadêmicos recentes da sociologia relacional, dos estudos urbanos e do neoinstitucionalismo têm nos mostrado que elementos de ao menos três tipos medeiam esses acessos. São eles associados aos padrões de vínculos sociais de que os indivíduos dispõem (suas redes), seus padrões de integração ou de isolamento espacial (a segregação) e elementos de formato e procedimento das políticas públicas, assim como dos próprios mercados econômicos (respectivamente instituições políticas e econômicas ou, mais amplamente, instituições sociais).

Assim, se são centrais para a presença de pobreza o próprio funcionamento das esferas produtoras de bem-estar (o funcionamento do mercado de trabalho, a presença de polí- ticas públicas universalistas, de comunidades e famílias integradoras, etc.), assim como a existência de atributos individuais que permitam participar dessas fontes de bem-estar (atributos de qualificação profissional para acessar mercados, atributos de cidadania legalizada para acessar políticas, pertencimentos do indivíduos a coletividades, etc.), são também essenciais as maneiras pelas quais os indivíduos acessam tais fontes. Dessa forma, acreditamos que perspectivas sobre a pobreza que a consideram meramente a partir da presença de estruturas de oportunidades (Kaztman \& Retamoso, 2005), assim como de ativos (Moser, 1998), perdem uma parte significativa dos elementos fundamentais na definição das condições de vida, situados nas estruturas de médio alcance que medeiam os acessos àquelas estruturas de oportunidades. Por essa razão, a consideração simultânea das redes e da segregação é essencial.

Já é relativamente vasta a literatura que conecta pobreza, segregação e redes sociais no âmbito internacional. De forma geral, o tema representou um desdobramento da agenda de estudos de segregação urbana, sendo analisado tanto de forma quantitativa, como em Briggs (2005) e Small (2007), como qualitativamente (Small, 2009; Mustered, Murie \& Kesteloot, 2006; e Blokland \& Savage, 2008). Em termos gerais, esses esforços representaram uma forma de precisar e testar vários dos elementos levantados pioneiramente por Wilson (1987) ao conectar o aumento da pobreza com a elevação do isolamento social e espacial nos guetos negros americanos em face de transformações econômicas de maior envergadura. Uma dimensão central nessa discussão é o grau de homofilia presente nos padrões de relações (McPherson et al., 2001), ou o quanto as redes conectam indivíduos com características distintas, ou se simplesmente vinculam pessoas similares socialmente ${ }^{1}$. A utilização das redes permitiria separar analiticamente (e testar separadamente) os efeitos dos dois tipos de isolamento - espacial e relacional.

A presente pesquisa também tem origem nesse tipo de preocupação. Desenvolvemos 
coletivamente no Centro de Estudos da Metrópole (CEM) diversos estudos sobre a associação entre pobreza e segregação. Seguindo uma abordagem mais tradicional (Marques \& Torres, 2005; CEM, 2004), esses estudos mostraram que a segregação tendia a ter um efeito negativo sobre a pobreza, mesmo quando controlado por outras dimensões sociais - indivíduos igualmente pobres mas submetidos diferentemente à segregação tendiam a ter condições sociais distintas, sendo as piores para os mais segregados. Entretanto, o efeito de isolamento da segregação em si poderia ser combatido, para determinados indivíduos, por suas redes sociais, que poderiam conectá-los "por sobre o território". Por essa razão, decidimos desenvolver uma pesquisa que analisasse simultaneamente os efeitos das redes sociais e da segregação sobre a pobreza.

\section{AS REDES EM SÃO PAULO E SALVADOR}

Antes de tudo precisamos apresentar as características gerais da pesquisa. Em primeiro lugar, é importante estabelecer que pesquisamos redes pessoais, e não redes totais ou de comunidades, ou egonets ${ }^{2}$, por considerar que os padrões de relação mais importantes para especificar as condições dos indivíduos são pessoais, mas não se limitam às vinculações diretas de que um dado ego dispõe. Esse procedimento permitiu obter redes de tamanho muito variado e com características muito distintas, o que consideramos que é compatível com a heterogeneidade que se pode esperar na sociabilidade dos indivíduos.

O estudo abrangeu duas fases de campo, uma em 2006-2007, na região metropolitana de São Paulo, e outra em 2009, na cidade de Salvador. Em São Paulo, foram realizadas entrevistas com 209 indivíduos em sete localidades escolhidas intencionalmente, levando em consideração estudos anteriores sobre pobreza urbana, de modo a cobrir a variabilidade de situações de segregação e de habitação na cidade. Os locais estudados incluem cortiços do centro de São Paulo, as favelas de Vila Nova Esperança, em Taboão da Serra, do Jaguaré e de Paraisópolis, em São Paulo, e Guinle, em Guarulhos, além de conjuntos habitacionais na Cidade Tiradentes e de uma área mista de favela e loteamento irregular no Jardim Ângela. Em Salvador, o trabalho de campo foi conduzido em cinco localidades, com base nos mesmos critérios, incluindo cortiços na área do Pelourinho, favelas em duas áreas consolidadas - Curuzu e Amaralina - e em duas regiões periféricas da cidade - o Bairro dos Cabritos, nos Alagados, e o Bairro da Paz -, totalizando 153 redes pessoais. A escolha dos locais de pesquisa considerou estudos anteriores, mas não partiu de uma delimitação prévia dos indivíduos que guiasse a pesquisa por qualquer corte preestabelecido de renda, condição de vida ou outros ${ }^{3}$. Para criar parâmetros para comparar as redes, foram construídas trinta redes de classe média em São Paulo.

Em cada campo a escolha dos entrevistados foi aleatória ao longo de percursos pelos locais estudados, sendo os indivíduos abordados em espaços públicos ou na entrada de suas casas, durante a semana e em fins de semana. A amostra de entrevistados foi controlada por alguns atributos sociais básicos, como sexo, idade, status migratório e ocupacional e área de moradia no local estudado.

Foram realizadas entrevistas egocentradas (quando se pergunta a um dado indivíduo sobre suas próprias relações) sobre a rede total de seu convívio pessoal, incluindo as várias esferas de sua sociabilidade. Esferas de sociabilidade são entendidas aqui como espaços cognitivamente reconhecidos pelos entrevistados como representando onde ocorre sua sociabilidade. Em primeiro lugar era aplicado um questionário semiestruturado referente às características gerais do entrevistado. A segunda parte das entrevistas incluiu a aplicação de uma ferramenta de coleta de dados relacionais com um gerador de nomes e perguntas sobre atributos dos nomes gerados. O gerador de nomes, por sua vez, envolveu duas etapas. A primeira, baseada em um breve relato sobre as principais dimensões
2 Essa distinção diz respeito a como os estudos representam os padrões de relações presentes em uma dada situação social, visto que as redes são instrumentos analíticos construídos a partir de nossas abstrações. Redes totais ou de comunidades são representações do conjunto de entidades e relações presentes em um contexto social,como um setor de política pública, uma empresa, uma aldeia indígena, um setor econômico ou uma mobilização social. Egonets são as redes centradas em indivíduos que consideram apenas seus vínculos primários e as relações entre eles, resultando em distâncias máximas não maiores que um passo.

3 Evitou-se com esse procedimento cair na discussão das linhas de pobreza ou no debate de como incorporar dimensões não econômicas nos parâmetros definidores das cotas a levantar. Na prática, a separação entre os indivíduos pobres e nãopobres no interior desses locais torna-se um problema empíri$\mathrm{co}$, visto que os modelos quantitativos de análise nos informarão sobre os casos discrepantes (outliers) que devem ser removidos da análise. 
da vida de cada indivíduo, visou construir uma "semente" de nomes para a segunda etapa a partir das esferas de sociabilidade. As esferas incluíram: familiar, vizinhança, amizade, associativa, diversão/lazer, estudos e profissional e/ou trabalho. Adicionalmente, solicitou-se aos entrevistados pensar em suas relações e citar um conjunto de no máximo cinco nomes para cada esfera de sociabilidade. Esses nomes constituíram a semente do gerador de nomes. Em seguida, solicitou-se que os entrevistados indicassem até três nomes associados a cada nome da semente, sendo aceitas repetições, assim como a indicação de si próprio. Os nomes novos eram acrescentados ao final da lista como a semente de uma nova rodada de entrevista com a mesma pessoa. $\mathrm{O}$ procedimento foi repetido três vezes, ou até que não houvesse mais nomes novos. O método nos forneceu um conjunto de díades (pares de nomes ligados por vínculos), indicando a presença de vínculos. Por fim, solicitamos aos entrevistados classificar os nomes citados segundo dois atributos: se o indivíduo é de fora ou de dentro da área estudada e a esfera de sociabilidade a que pertence. Em todos os casos, os valores preestabelecidos para os atributos podiam ser alterados na própria entrevista, considerando a alta especificidade das trajetórias, esferas de sociabilidade e das próprias redes.

Em cada uma das cidades, depois de analisar os dados relacionais e construir as redes, retornamos a campo para realizar entrevistas qualitativas com indivíduos selecionados a partir de uma combinação de características individuais e das redes pessoais. Essas entrevistas exploraram a forma pela qual 38 indivíduos com diferentes tipos de redes as mobilizam para a resolução de problemas cotidianos por meio de apoio social, em situações como migração, obtenção de trabalhos, cuidados com crianças e idosos, apoio emocional, etc. A mobilização das redes no caso de São Paulo foi analisada em detalhes por Marques (2010) e não é explorada aqui.

Esses procedimentos levaram à construção de um banco de dados com as informações dos 352 entrevistados e suas redes.
A apresentação de algumas informações básicas sobre os entrevistados ajuda a situar a pesquisa, antes de discutirmos as redes propriamente ditas. Em termos etários, os entrevistados variavam entre 12 e 94 anos, mas com uma grande concentração na idade adulta e médias de idade de 36 anos em São Paulo e 38 em Salvador.

Nos dois casos foram entrevistadas mais mulheres que homens. Em São Paulo as mulheres correspondem a $57 \%$ da amostra, em Salvador elas representam 55\%. Também é semelhante a distribuição no que diz respeito ao estado civil: em Salvador, $50 \%$ dos entrevistados vivem com companheiro, já em São Paulo a proporção é de $56 \%$.

As duas cidades se diferenciam bastante em relação à cor da pele (classificada pelos entrevistadores): enquanto em São Paulo 42,4\% dos entrevistados foram classificados como de cor preta, em Salvador a população com essa característica representa $74 \%$ da amostra.

Outra diferença marcante entre as cidades diz respeito à migração. Em São Paulo 70,3\% dos entrevistados eram migrantes; já em Salvador apenas 34\% não eram nativos de Salvador. Analisando apenas os migrantes nas duas cidades, também encontramos algumas diferenças importantes. Em Salvador, dentre os migrantes, apenas $11 \%$ estão na cidade há menos de dez anos; já em São Paulo 30\% dos migrantes se encontram nessa mesma condição. Além da baixa migração, Salvador parece ser caracterizada pela pequena mobilidade dos indivíduos em relação a São Paulo. Enquanto, em São Paulo, 54\% dos entrevistados moram há mais de dez anos no mesmo bairro, em Salvador $88 \%$ dos entrevistados possuem essa característica. De fato, o localismo (a proporção dos indivíduos de uma dada rede que habita o mesmo local do entrevistado) é superior em Salvador e uma das principais diferenças entre as redes nas duas cidades (Castello \& Marques, 2010).

Em relação à religião observamos que a proporção de evangélicos nas duas cidades é idêntica, 24\%, embora haja variações com relação às demais religiões. Enquanto em São Paulo 63\% dos entrevistados se diziam cató- 
licos e $12 \%$ não tinham religião, em Salvador apenas $45 \%$ dos entrevistados afirmavam ser católicos, $22 \%$ diziam não ter religião e $8 \%$ indicavam que seguiam o candomblé. Ainda em relação às práticas religiosas, os dados indicam maior frequência a templos na capital baiana. Em Salvador, $45 \%$ dos entrevistados afirmaram frequentar ao menos uma vez por semana o culto de sua religião, enquanto em São Paulo apenas 36\% disseram frequentar cultos pelo menos uma vez por semana.

A presença de práticas associativas é baixa nas duas cidades, embora mais elevada em Salvador: em São Paulo, 8\% dos entrevistados disseram participar de alguma associação; já em Salvador 16\% afirmaram a mesma coisa.

Analisando as variáveis relativas à escolaridade e à inserção no mercado de trabalho, observamos outras distinções interessantes. Em São Paulo os entrevistados tendiam a ter escolaridade mais baixa - em média seis anos de estudo, contra média de sete anos de estudo em Salvador. O mesmo tipo de resultado foi obtido no que diz respeito à população com mais alta escolaridade. Em Salvador, $27 \%$ dos entrevistados concluíram o ensino médio e quase $6 \%$ deles chegaram à universidade, enquanto em São Paulo apenas $16 \%$ dos entrevistados tinham o ensino médio completo e menos de $4 \%$ da amostra chegou à universidade.

Essas posições relativas foram invertidas no caso do rendimento: $19 \%$ em São Paulo e $22 \%$ em Salvador tinham renda familiar per capita inferior a $1 / 4$ do salário mínimo. A média de renda familiar per capita em São Paulo era de 0,82 salário mínimo, enquanto em Salvador a média era de 0,77 .

Quanto aos indivíduos ativos no mercado de trabalho, a maior diferença está na maior proporção de autônomos (bicos) em Salvador (32,7\%) do que em São Paulo (20,6\%). Há mais empregados com registro na carteira em São Paulo (16,3\%), embora a diferença com relação a Salvador não seja tão expressiva $(11,8 \%)$, assim como mais empregados sem registro em carteira em São Paulo $(8,1 \%)$ do que em Salvador (4,6\%). Considerando-se os não ativos, as diferenças mais expressivas encontram-se na maior presença de donas de casa $(17,7 \%)$ em São Paulo do que em Salvador (5,2\%), e maior presença de aposentados em Salvador (11,1\%) contra 2,9\% em São Paulo.

Os níveis de desemprego se assemelham 11,5\% em São Paulo e 13,1\% em Salvador -, embora a precariedade do trabalho fosse maior em Salvador $(64,9 \%)$ do que em São Paulo (57,9\%). O emprego protegido (com registro em carteira, proprietário e negócio familiar) também está mais presente em São Paulo $(40,7 \%)$ do que em Salvador $(31,6 \%)$ em relação à média de $36,7 \%$.

A segregação está presente em parte significativa dos domicílios que contemplam a amostra em ambas as cidades: $43 \%$ e $34 \%$ dos indivíduos entrevistados em São Paulo e Salvador, respectivamente, viviam em locais segregados, ou seja, espacialmente distantes/ isolados dos centros econômicos das cidades, e relativamente homogêneos internamente.

As redes analisadas apresentaram tamanhos e complexidades muito variados, embora essas variações tenham sido similares entre as cidades. Em Salvador, em média, as redes tinham 41 nós - variando de 8 a 185 nós - e 74 vínculos, variando de 10 a 387. Em São Paulo, nossos entrevistados apresentaram redes com em média 53 nós, variando de 4 a 179 vínculos. É interessante observar que, enquanto o número médio de nós se apresentava maior em São Paulo, em Salvador as redes se destacavam por ter um número médio maior de vínculos. Por outro lado, para termos um parâmetro de comparação, vale reportar que as redes de classe média em São Paulo apresentaram 92 nós e 183 vínculos, em média. Isso sugere que as variações das redes de pobres entre São Paulo e Salvador eram relativamente pequenas e tendiam em ambos os casos a ser substancialmente menores do que redes de classe média.

Considerando as esferas de sociabilidade, as redes em Salvador tinham em média 3,5 esferas, variando de 2 a 8 esferas, enquanto em São Paulo a média era de 3,8 esferas, variando de 1 a 7. Essa classificação não diz respeito aos tipos de vínculo, como parentesco, por exemplo (dado não coletado sistema- 
ticamente pela pesquisa), nem a atributos dos nós, como ser primo ou irmão, novamente para exemplificar. Consequentemente, um dado entrevistado pode afirmar que mantém relações com um primo (que tem atributos de parente) através de uma relação de amizade (que é um tipo de vínculo) no interior da esfera da vizinhança, se assim informar. E com relação às esferas de sociabilidade, novamente as redes da classe média apresentaram características muito distintas das redes de indivíduos em situação de pobreza, alcançando 5,5 esferas diferentes, em média. Portanto, novamente as redes dos pobres tendem a variar pouco entre si entre cidades, embora distem bastante das de classe média.

Talvez a mais importante diferença entre as redes das duas cidades diga respeito ao localismo. Em Salvador encontramos redes proporcionalmente mais locais que em São Paulo - 63,5\% na capital baiana contra
60,5\% em São Paulo. A diferença novamente não parece ser muito elevada se considerarmos que o localismo médio entre a classe média era de $18 \%$. Mas uma análise detalhada do fenômeno (Castello \& Marques, 2010) indicou redes sistematicamente mais locais em Salvador, em todas as esferas de sociabilidade, mas mais intensamente nas esferas de sociabilidade potencialmente menos homofílicas - igreja, trabalho e associações. Assim, o mais alto localismo de Salvador se associa a maior homofilia potencial, com efeitos sobre a circulação de informações e oportunidades nas duas cidades.

Portanto, as redes de São Paulo e de Salvador não são muito diferentes ${ }^{4}$, embora sejam muito diversas das de indivíduos da classe média. Esse resultado repete o já encontrado em São Paulo, permitindo sustentar que as redes de indivíduos em situação de pobreza tendem a ser menores, em média,
4 Foram calculados diversos outros indicadores, não discutidos aqui por razões de espaço. Em Salvador a densidade média das redes era de 0,14 ; o diâmetro médio, 5,5; o grau médio, 12,14; ocoeficiente de clusterização médio, 0,519. Em São Paulo, observamos que a densidade média das redes era de 0,10 ; o diâmetro médio, 6,2; o grau médio, 8,2; o coeficiente de clusterização médio, 0,46 . Dentre a classe média o diâmetro médio era 7,4 ; o grau médio, 6,00 , e o coeficiente de clusterização médio, 0,560.
GRÁFICO 1

\section{TAMANHO, LOCALISMO E ESFERAS DE SOCIABILIDADE POR TIPO DE REDE}

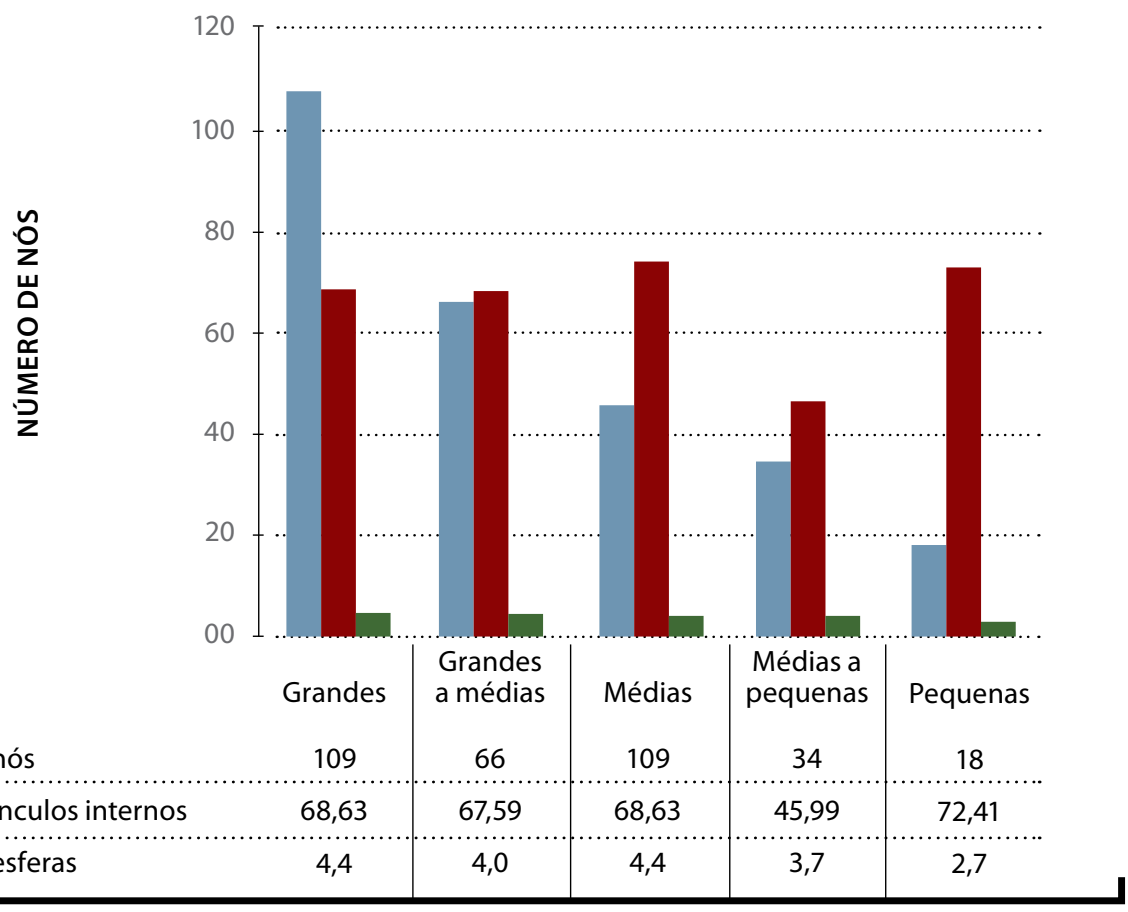

Fonte: elaboração própria baseada na coleta de dados empíricos 
menos diversificadas em termos de sociabilidade e mais locais do que as redes de classe média. Isso reforça resultados anteriores de Fischer e Shavit (1995), Grosseti (2007) e Lonkila (2010), que sugerem que as redes tendem a variar menos entre sociedades e contextos culturas distintos (ao menos as de apoio pessoal, estudadas por tais autores) do que entre grupos sociais dentro de uma mesma sociedade.

Entretanto, independentemente de suas características médias, as redes tendem a variar consideravelmente dentro de cada grupo - entre os pobres, bem como na classe média. Isso sugeriu que para explorarmos as redes seria preciso analisar a sua heterogeneidade. Isso foi realizado através da utilização de duas análises de agrupamentos com medidas das redes ${ }^{5}$, assim como os perfis de sociabilidade por esfera contidos nas redes. No caso da primeira tipologia, encontramos cinco tipos de redes, variando das maiores até as menores, sendo que as de tamanho médio apresentavam a menor presença de localismo. O Gráfico 1 resume a informação.

Por outro lado, a tipologia baseada nas esferas de sociabilidade indicou a existência de seis tipos diferentes de redes considerando a presença proporcional de cada uma das esferas principais de sociabilidade. A Tabela 1 apresenta a informação, mostrando concentração nas esferas da família, da vizinhança, dos amigos, da igreja, do trabalho e de associações, respectivamente.

Se encontramos cinco tipos de redes e seis tipos de sociabilidade, poderíamos ter trinta situações potencialmente. Entretanto, o cruzamento das tipologias e a análise do significado das situações com relação à homofilia potencial, ao localismo e à variabilidade da sociabilidade indicaram quatro combinações, que contemplam $92,4 \%$ do

TABELA 1

\section{TIPOS DE SOCIABILIDADE DE ACORDO COM ESFERAS DE SOCIABILIDADE (\%)}

\begin{tabular}{|c|c|c|c|c|c|c|c|}
\hline ESFERAS & & & IPO DE SO & BILIDA & & & \\
\hline & Família & Vizinhança & Amizade & Igreja & Trabalho & Associação & Total \\
\hline Família & 64,07 & 28,75 & 37,41 & 33,34 & 31,37 & 34,47 & 40,57 \\
\hline Vizinhança & 20,68 & 57,08 & 23,96 & 25,32 & 26,41 & 24,80 & 31,61 \\
\hline Amizade & & & 26,22 & 1,84 & 1,65 & & 5,89 \\
\hline Trabalho & & & & 6,16 & 29,05 & & 8,05 \\
\hline Lazer & & & & & & & 1,88 \\
\hline Igreja & & & & 25,02 & & & 4,56 \\
\hline Associação & & & & & & 19,01 & 1,40 \\
\hline Estudos & & & & & & & 3,34 \\
\hline $\begin{array}{l}\text { Outros } \\
\text {............ }\end{array}$ & & & & & & & $\begin{array}{r}1,21 \\
\ldots \ldots \ldots\end{array}$ \\
\hline $\mathrm{N}^{\circ}$ de Casos & 94 & 86 & 57 & 48 & 55 & 22 & 362 \\
\hline
\end{tabular}

Fonte: elaboração própria baseada na coleta de dados empíricos

Nota: porcentagens abaixo de $6 \%$ foram omitidas. Células possuem porcentagens acima da média e células representam concentrações significativas, apesar de estar abaixo da média.
5 Utilizando as seguintes medidas: número de nós, número de vínculos, diâmetro, grau médio, centralização, coeficiente de clusterização, E-líndices, n-clans, intermediação, informação, buracos estruturais, número de contextos e número de esferas. 
6 As definições utilizadas foram as seguintes:existe precariedade de renda quando a média da renda domiciliar per capita é igual ou inferior a 1/4 de salário mínimo; existe precariedade familiar em situações nas quais o núcleo familiar é composto por um único provedor adulto com crianças pequenas; existe precariedade de habitação quando a habitação é um barraco de madeira ou um quarto sem banheiro; existe precariedade de trabalho quando a renda é adquirida de maneira informal, através de bicos ocasionais ou trabalho em vínculo informal sem continuidade no tempo.

7 Relacionais: número de nós da rede individual, número de vínculos, grau médio, tamanho eficiente da rede egocentrada, centralização, coeficiente de clusterização, proporção de pessoas externas à área, número total de esferas, variáveis dicotômicas (dummy) referentes aos tipos de redes com cinco grupos, variáveis dicotômicas (dummy) total das redes pessoais analisadas. São elas: a) sociabilidade primária em redes pequenas; b) sociabilidade primária em redes médias; c) sociabilidade primária em redes grandes;

d) sociabilidade organizacional em redes médias.

Os quatro tipos estão igualmente presentes em São Paulo e Salvador, mas, como veremos a seguir, estão associados de forma bastante distinta às condições sociais dos indivíduos.

\section{REDES E VULNERABILIDADE SOCIAL}

Completada a análise descritiva básica das redes, já estamos em condição de investigar as associações entre atributos dos indivíduos, variáveis relacionais e de sociabilidade, e vulnerabilidade social. Embora todos os entrevistados sejam pobres, há importantes diferenças nos seus níveis de pobreza. Assim, decidimos testar os condicionantes da presença de situações de elevada precariedade social, que separa os indivíduos mais precários entre os pobres. Para tal, buscamos explicar um indicador sintético de precariedade composto por dimensões familiares, habitacionais de renda e de trabalho ${ }^{6}$. Consideramos como "precários" os indivíduos com duas ou mais dentre as quatro condições, sendo todos os demais indivíduos considerados como não precários. Apresentavam precariedade segundo essa definição $24 \%$ dos entrevistados, sendo não precários os restantes $76 \%$.

A análise dessa associação foi realizada utilizando um método exploratório conhecido como árvore de Chaid (Chi-squared automatic Interaction Detection). Esse método testa as relações entre uma variável dependente, necessariamente categórica, e outras preditoras, a partir da estatística qui-quadrado. A cada nível da árvore, o procedimento compara a variável dependente com cada uma das independentes isoladamente, escolhendo a que apresenta associação com mais alta significância (considerando a estatística qui-quadrado) ${ }^{7}$. O conjunto dos casos é então dividido segundo os valores dessa variável independente, e cada subgrupo é novamente comparado com cada uma das independentes resultantes, escolhendo-se a que apresentar maior associação. O procedimento é repetido até que não haja mais associações significativas ou que os subgrupos não apresentem casos suficientes para a análise prosseguir. $\mathrm{O}$ modelo resultante é o apresentado na Figura $3^{8}$.

O modelo mostra que o indicador composto de precariedade está associado à sociabilidade centrada em ambientes organizacionais. Dentre aqueles que têm esse tipo de sociabilidade, a precariedade envolve apenas 9,2\% das pessoas, enquanto entre os indivíduos com todos os demais perfis de sociabilidade a precariedade atinge $31 \%$, em média. Por outro lado, o segundo nível da árvore nos indica que dentre aqueles que não têm sociabilidade organizacional, a migração é um segundo fator predominante. Para os migrantes a presença de precariedade é de $36,7 \%$, enquanto para os não migrantes alcança apenas $21,7 \%$. O terceiro nível especifica a situação dos migrantes que não têm sociabilidade organizacional. Dentre eles, os que contam com sociabilidade centrada na família têm situação de precariedade menos frequente $-23,7 \%$, contra $45,1 \%$ dos que têm sociabilidades de outros tipos (na vizinhança e entre amigos, dado o primeiro nível da árvore). O modelo classificou 76,2\% dos casos corretamente.

Portanto, tipos de sociabilidade e de redes se mostram centrais, embora nesse caso associados ao status migratório. A interpretação do resultado nos parece clara: o elemento mais fortemente associado à ausência de precariedade entre os pobres é a presença de sociabilidades organizacionais. $\mathrm{Na}$ ausência dessas, dimensões associadas à maior ou menor integração social no local de moradia podem mitigar a situação. Os migrantes, por contarem com menos recursos de vários tipos, tendem a apresentar situação mais precária do que os não migrantes. Mas, mesmo entre os migrantes, os que contam com um contexto familiar forte em termos relacionais podem reduzir as chances de cair em situações precárias. A importância 


\section{FIGURA 3}

\section{ANÁLISE DE CHAID DE PRECARIEDADE, SÃO PAULO E SALVADOR}

Precariedade - se ao menos duas das condições de precariedade aplicáveis estão presentes

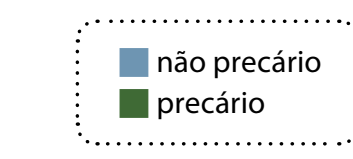

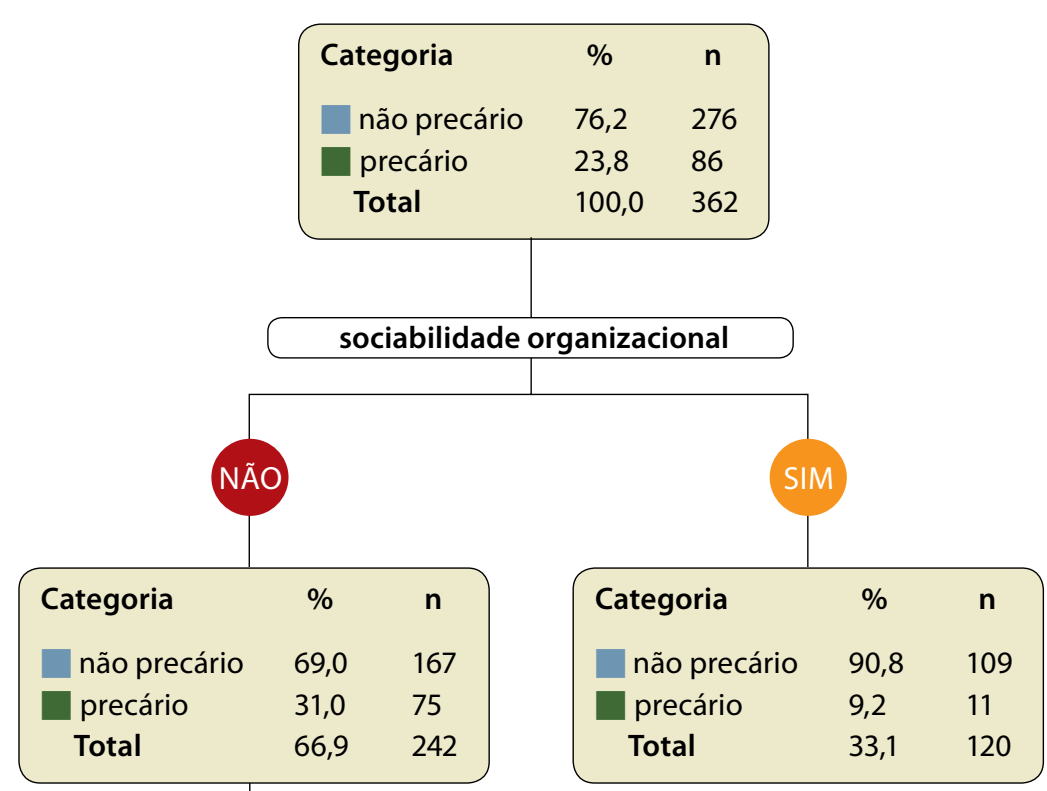

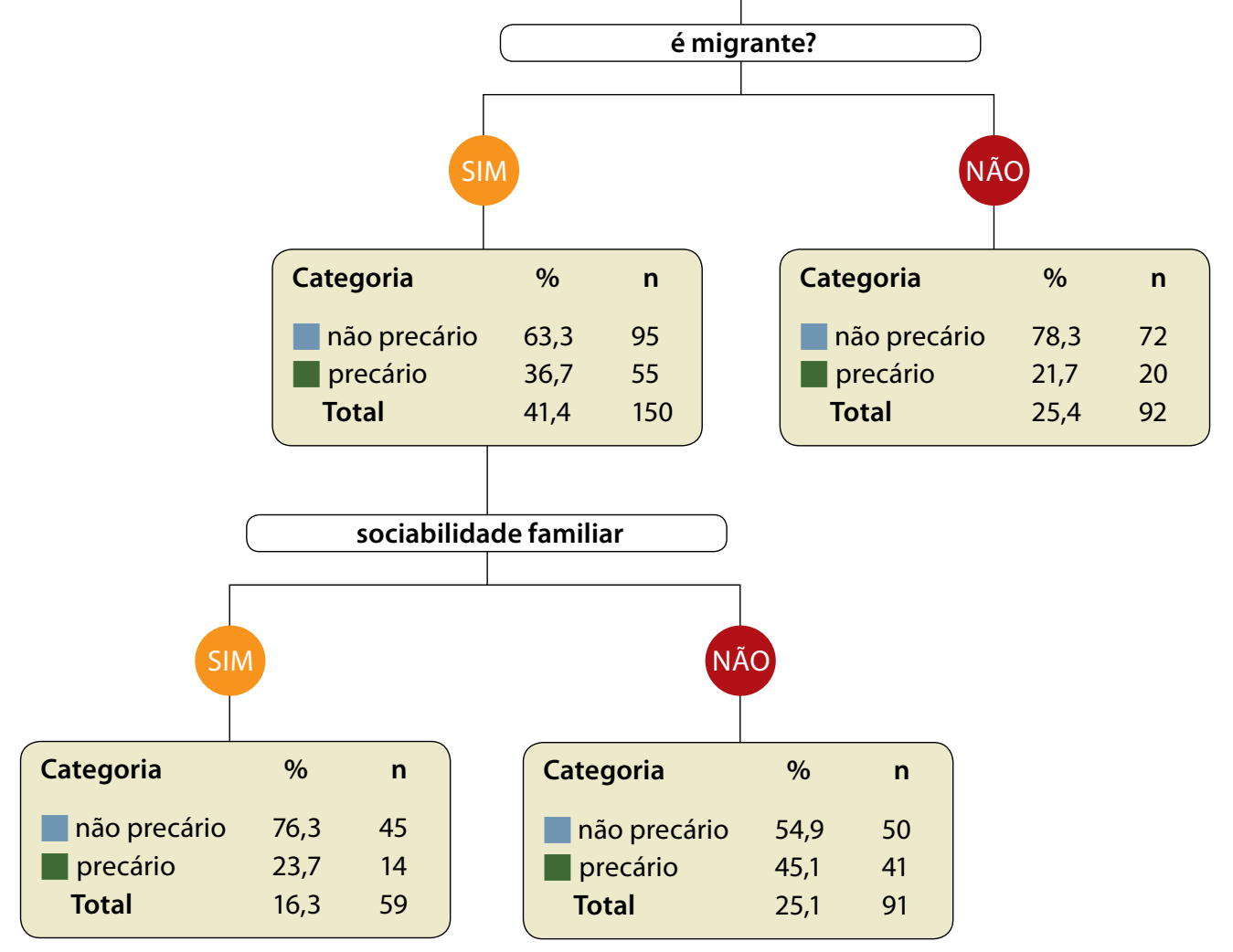

Fonte: análise dos autores a partir de dados de campo 
referentes aos tipos de sociabilidade e de rede, assim como às suas combinações; socioeconômicas: sexo do indivíduo, anos de estudo, frequenta igreja ou templo mais do que quinzenalmente; participa de alguma associação; etárias: idade do indivíduo, idoso (60 anos ou mais), jovem (idade menor ou igual a 21 anos). Pormotivosóbviosas variáveis associadas a renda e emprego não foram incluídas no modelo, visto que fazem parte da definição da variável dependente. A variável "segregado" também foi retirada, pois se encontra correlacionada por definição com os cortiços e, consequentemente, com a definição de precariedade habitacional.

8 Vale reportar que, quando os casos de classe média são incluídos nas análises, a primeira variável em todas as árvores que se seguem é a escolaridade, indicando que, entre grupos sociais, o seu poder de discriminação social é muito significativo. Apenas entre os pobres, entretanto, tanto a sua variação quanto a sua associação com outros atributos se enfraquecem, sendo suplantadas por dimensões associadas às sociabilidade e às redes. da sociabilidade familiar, entretanto, apenas especifica a situação de quem já não teve acesso às formas de integração anteriores.

A diferença entre as situações polares - $35,9 \%$ (de $45,1 \%$ a $9,2 \%$ ) - indica que as redes e sociabilidades discriminam substancialmente as situações sociais. O modelo encontrado apenas para os casos de São Paulo é praticamente idêntico 9 .

\section{CONCLUSÃO}

Nesta conclusão retomamos os principais resultados apresentados ao longo do artigo. Vimos que as redes de indivíduos em situação de pobreza não variam muito entre São Paulo e Salvador em suas características médias, apesar das grandes diferenças entre as cidades. A dimensão que apresentou maiores diferenças disse respeito ao localismo, sendo os padrões de relação em Salvador mais locais do que em São Paulo, o que foi explicado pela maior consolidação dos bairros na capital baiana, tendo como consequência que a maior parte dos moradores habita no mesmo local de maneira estável há muito mais tempo do que seus congêneres em São Paulo.

Por outro lado, encontramos grandes diferenças entre as redes de indivíduos pobres e de classe média, sendo as dos primeiros menores, menos variadas em termos de sociabilidade, mais locais e mais centradas em esferas potencialmente homofílicas. Apesar disso, as redes também variaram intensamente entre os pobres, sugerindo a existência de padrões heterogêneos no interior dos grupos sociais. A construção de tipologias comprovou esse achado, mostrando que, se podemos encontrar entre os pobres redes locais e potencialmente homofílicas (tanto grandes quanto pequenas), também se fazem presentes redes pouco locais, potencialmente menos homofílicas e de tamanho médio.

A análise quantitativa posterior mostrou que os tipos de rede e de sociabilidade estão fortemente associados a situações de vulnerabilidade social. Sociabilidades construídas de forma intensa em ambientes organizacionais, assim como sociabilidades mais variadas, se associam a melhores condições sociais. Para os indivíduos que não contam com tais padrões de sociabilidade, entretanto, a presença de sociabilidade na família e o fato de ser não migrante podem atenuar a presença dessas situações.

Portanto, os padrões de relações dos indivíduos são centrais para a explicação das suas condições sociais. Redes e sociabilidade mais locais, potencialmente mais homofílicas, e menos variadas, tendem a se associar sistematicamente com piores condições sociais. Dentre as várias consequências desses resultados, vale terminar este artigo destacando o caráter de circularidade presente na associação entre esses elementos, contribuindo potencialmente para a perpetuação da pobreza de forma persistente.

\section{BIBLIOGRAFIA}

BIDART, C.; LAVENU, D. "Evolution of Personal Networks and Life Events", in Social Networks, 27 (4), 2005, pp. 359-76.

BLOKLAND, T.; SAVAGE, M. Social Capital and Networked Urbanism. London, Basil

Blackwell, 2008.

BRIGGS, X. "Social Capital and Segregation in the United States", in D. Varady.

Desegregating the City. Albany, Suny Press, 2005.

CEM - CENTRO DE ESTUDOS DA METRÓPOLE. Mapa da Vulnerabilidade Social da

População da Cidade de São Paulo. São Paulo, CEM/Cebrap/SAS/PMSP, 2004. 
DEGENNE, A. "Tipos de Interacciones, Formas de Confiança y Relaciones", in Redes Revista Hispana para el Análisis de Redes Sociales, vol. 16 (3), 2009, pp. 63-91.

ESPING-ANDERSEN, G. Fundamentos Sociales de las Economías Postindustriales. Barcelona, Ariel, 2000.

FISCHER, C.; SHAVIT, Y. "National Differences in Network Density: Israel and the United States", in Social Networks, 17(2), 1995, pp. 129-45.

GROSSETI, M. "Where do Social Relations Came From?", in Social Networks,27.

HEDSTROM, P.; SANDELL, R.; STERN, C. "Meso-level Networks and the Diffusion of Social Movements", in American Journal of Sociology, 106 (1), 2000, pp. 145-72.

HEINZ, J.; LAUMANN, E.; NELSON, R.; SALISBURY, R. Hollow Core: Private Interests in National Policy Making. Cambridge, Harvard University Press, 1997.

KAZTMAN, R.; RETAMOSO, A. "Spatial Segregation, Employment and Poverty in Montevideo", in Cepal Review, 85, 2005, pp. 125-42.

KNOKE, D.; PAPPI, F.; BROADBENT, J.; TSUJINAKA, Y. Comparing Policy Networks: Labor Politics in the U.S., Germany, and Japan. Cambridge, Cambridge University Press, 1996.

LONKILA, M. "The Importance of Work-related Social Ties in Post-soviet Russia: the Role of Co-workers in the Personal Networks in St. Petersburg and Helsinki", in Connections, vol. 30(1), 2010, pp. 46-56.

MARQUES, E. Redes Sociais, Segregação e Pobreza. São Paulo, Ed. Unesp/CEM, 2010.

MARQUES, E.; TORRES, H. São Paulo: Segregação, Pobreza Urbana e Desigualdade Social.

São Paulo, Ed. Senac, 2005.

MCPHERSON, M.; SMITH-LOVIN, L.; COOK, J. "Birds of a Feather: Homophily in Social Networks", in Annual Review of Sociology, 27, 2001, pp. 415-44.

MISCHE, A. Partisan Publics. Princeton, Princeton University Press, 2008.

MOSER, C. "The Asset Vulnerability Framework: Reassessing Urban Poverty Reduction Strategies", in World Development, vol. 26(1), 1998, pp. 1-19.

MUSTERED, S.; MURIE, A.; KESTELLOT, C. Neighborhoods of Poverty: Urban Social Exclusion and Integration in Europe. London, Palgrave Ed., 2006.

SMALL, M. "Racial Differences in Networks: Do Neighborhood Conditions Matter?", in Social Science Quarterly, vol. 88 (2), 2007.

Unanticipated Gains: Origins of Network Inequality in Everyday Life. Oxford,

Oxford University Press, 2009.

WILSON, W. The Truly Disadvantage: the Inner City, the Underclass and Public Policy.

University Chicago Press, 1987.
9 No caso da precariedade, a diferença com o caso de São Paulo diz respeito à ordem explicativa da migração e da sociabilidade familiar-em Marques (2010), sociabilidade familiar apareceu no segundo nível e migração no terceiro. Os grupos finais, portanto, são levemente diferentes, e a pior situação em São Paulo diz respeito à ausência de sociabilidade organizacional também de sociabilidade familiar, sem indicação relativa à migração, enquanto aqui diz respeito a migrantes com ausência desociabilidadeorganizacional e de sociabilidade familiar (na prática, sociabilidade na vizinhança ou entre amigos). Em São Paulo, a combinação entre sociabilidade familiar e migração especificava situações intermediárias. 